\title{
Factors Involved in the Selection of Treatment in Patients with Hematological Malignancies
}

\author{
Guillermo J. Ruiz-Argüelles \\ Centro de Hematología y Medicina Interna de Puebla, Puebla, Mexico
}

In this issue of Acta Haematologica, Wang et al. [1] examine the usefulness of using the combination of cladribine, cytarabine, and filgrastim (CLAG) in the treatment of patients with refractory or relapsed acute myelogenous leukemia. The favorable outcome of these patients supports the effectiveness of this combination. Cladribine seems to properly replace fludarabine in this combination specified in the FLAG schedule [2]. In several countries, Mexico included, cladribine is substantially more expensive than fludarabine. As a result, despite the fact that CLAG could be better than FLAG, in some countries, CLAG cannot be given because it is economically unaffordable; this could, however, be different in other settings. Along the same line, the increasing costs of the novel drugs employed in the treatment of hematological malignancies has dramatically changed the way of choosing between the therapeutic options [3], which nowadays depends not only on the cost-benefit ratio of the drug or therapeutic maneuver but also on the insurance of the patients (if any), the economic situation of their living country, the type of social security system they belong to, the ethics of the physician who takes care of them, the attendance of congresses abroad of the prescribing physician, the rules of the industry-physician relation in each country, the reliability of the key opinion leaders chosen by the industry, the type of training that the key opinion leaders undergo, etc. [4].
The decision of choosing a therapeutic approach for a given patient should rely, ideally, only on the effectiveness of the treatment and not on the above-mentioned variables. In the practice of hematology, something should be done before the gap between effectiveness for the patient and benefit for the industry/physician further deepens. The well-being of the patient should always be the main concern in medical practice.

\section{KARGER}

(c) 2018 S. Karger AG, Basel

1 Wang L, Xub J, Tian X, Lv T, Yuan G. Analysis of efficacy and prognostic factors of CLAG treatment in Chinese patients with refractory or relapsed acute myeloid leukemia. Acta Haematol. DOI: 10.1159/000493250.

2 Estey E, Thall P, Andreeff M, Beran M, Kantarjian $\mathrm{H}, \mathrm{O}$ 'Brien $\mathrm{S}$, et al. Use of granulocyte colony-stimulating factor before, during, and after fludarabine plus cytarabine induction therapy of newly diagnosed acute myelogenous leukemia or myelodysplastic syndromes: comparison with fludarabine plus cytarabine without granulocyte colony-stimulating factor. J Clin Oncol. 1994 Apr;12(4):671-8.

3 Ruiz-Argüelles GJ, Steensma DP. Staunching the rising costs of haematological health care. Lancet Haematol. 2016 Oct;3(10):e455.

4 Ruiz-Argüelles GJ. A new breed in the teaching of medicine: paid lecturers, trainers or speakers. Acta Haematol. 2016;135(3):191-2. 